\title{
Uma experiência prática da inserção da robótica e seus beneficios como ferramenta educativa em escolas públicas
}

\author{
Rosaine Fiorio ${ }^{1}$, Rauany J. Esperandim ${ }^{1}$, Flávio A. Silva ${ }^{1}$, Paulo J. Varela ${ }^{1}$, Maici \\ Duarte Leite ${ }^{1}$, Francisco Antonio Fernandes Reinaldo ${ }^{1}$ \\ ${ }^{1}$ Coordenação de Licenciatura em Informática - Universidade Tecnológica Federal do \\ Paraná (UTFPR) \\ Caixa Postal 135 - 85.601-970 - Francisco Beltrão - PR - Brazil \\ \{rosainefiorio, raulesperandim\}@gmail.com, \{flaviosilva, paulovarela, \\ maicileite\} eutfpr.edu.br
}

\begin{abstract}
The Educational Robotics emerged as didactic proposal in order to explore the concepts in the school curriculum, with the goal of making learning more attractive. The activities were conducted in schools participating in the Institutional Program for Introduction to Teaching (IPIT), where one of the difficulties was the apparent fear of teachers to use technological resources, such as Lego Mindstorms kits, to assist them in the teaching process. So much student as teacher can benefit from play activities through robotics. This practice presents interesting because it falls within the school the axis of application of Information Technologies and Communication. As a result of the study discusses the importance of using technologies among the living.
\end{abstract}

Resumo. A Robótica Educativa surgiu como proposta didática com o intuito de explorar conceitos presentes no currículo escolar, com o objetivo de tornar a aprendizagem mais atrativa. As atividades foram desenvolvidas em escolas participantes do Programa Institucional de Iniciação à Docência (PIBID), onde uma das dificuldades encontradas foi o aparente receio de professores em utilizar recursos tecnológicos, como os kits Lego Mindstorms, para auxiliá-los no processo de ensino-aprendizagem. Sendo assim, tanto aluno como professor podem se beneficiar das atividades lúdicas através da robótica. Esta prática se apresenta interessante, pois insere no espaço escolar o eixo de aplicação das Tecnologias da Informação e da Comunicação. Como resultado do estudo discute-se a importância da utilização de tecnologias dentro de sala.

\section{Introdução}

Aulas pouco motivadas em laboratórios computacionais comumente refletem professores sem treinamento tecnológico, má utilização de recursos midiáticos, laboratórios pouco utilizados e frustração com o uso de recursos trivais como quadro e giz. A realidade se apresenta em escolas públicas municipais e estaduais principalmente localizadas em comunidades carentes (Dotta, Barboza, Góis, Giordan, 2010).

A correta identificação e aplicação de Tecnologias da Informação e Comunicação (TICs) em sala de aula tem permitido uma nova releitura no processo de ensino-aprendizagem, motivando os alunos ao despertar escolar (Braga, Dotta, Pimentel, 2013). 
Um exemplo comum nas escolas públicas são laboratórios subutilizados, que poderiam fazer parte das aulas como atividades práticas e que incentivariam o aluno em seu processo de aprendizagem e, muitas vezes, no seu desenvolvimento pessoal e, futuramente, profissional. Além disso, a inserção de tecnologias como método didático pode se mostrar promissora para aumentar a sede por conhecimento e o desenvolvimento de muitas outras habilidades necessárias ao aluno.

No sentido de explorar um recurso com viés distinto do Laboratório de Informática, em escolas públicas, algumas outras propostas vêm surgindo, como é o da Robótica Educacional.

A robótica traz uma possibilidade de mudança desse cenário, visto que o assunto desperta interesse em todas as idades, a sua aplicação dentro do ambiente escolar pode trazer benefícios tanto para o professor quanto para o aluno. Os conceitos da Matemática, Física, Mecânica, Mecatrônica e até mesmo História e Biologia tornandose uma das diversas tecnologias passíveis de utilização dentro das escolas, podendo oferecer ao aluno oportunidades de experimentar novos ambientes de aprendizagem, em especial com a robótica, estimulando os alunos "aprenderem" a "aprender" (Medeiros Filho e Gonçalves, 2008). Também proporciona atividades, que além de desafiar tende a motivar o aluno, uma vez que utiliza da criatividade e lógica do aluno na apresentação de soluções de hardware e software, a partir da resolução de uma situação-problema (Miranda, Sampaio, Borges, 2010).

Sendo assim, este artigo tem como objetivo geral analisar se houve e quais foram as mudanças no comportamento dos alunos que participaram do curso de robótica do PIBID da Universidade Tecnológica Federal do Paraná do campus de Francisco Beltrão do curso de Licenciatura em Informática nas suas primeiras experiências como docente.

\section{Robótica e PIBID}

A robótica vem causando grande impacto na sociedade por trazer inovações em diversos setores. Seja por necessitar de aprimoramento dos trabalhadores para a manipulação desta tecnologia em alguns tipos de postos de trabalhos, sejana criação outros postos. Um exemplo de utilização é encontrado na medicina, onde médicos realizam intervenções cirúrgicas delicadas a distância, também existem robôs para o uso doméstico, como roomba que é um aspirador de pó totalmente autônomo.

Já em chão de fábrica (utilização industrial) não é possível mensurar o amplo uso de robôs, onde realizam atividades repetitivas e de precisão. Desde 1997 a NASA envia seus robôs para exploração de planetas do sistema solar, como no caso dos robôs Spirit, Opportunity, Sojourner e Curiosity, todos enviados a Marte. Com isso, percebese que a Robótica tem seu maior apelo no uso em situações e ambientes inóspitos, aqueles onde um Ser Humano não pode trabalhar ou ter condições de trabalho. Além de situações onde a precisão e rapidez são necessárias. Porém, é de vontade dos roboticistas que existam robôs em todos os setores e no cotidiano, mas que não haja substituição de mão de obra Humana, apenas adaptação desta. 


\subsection{Robótica Educativa}

A robótica educativa visa levar o aluno a questionar, pensar e procurar soluções, saindo da teoria para a prática usando ensinamentos obtidos em sala de aula, na vivência cotidiana, nos relacionamentos, nos conceitos e valores.

A robótica se destaca como ferramenta educacional atrativa e estimulante, servindo de apoio a aprendizagem pela possibilidade em se atuar com uma gama ampla de possibilidades estratégica no ensino dos diferentes componentes curriculares (Medeiros Filho e Gonçalves, 2008; Benitti, Vahldick, Urban, Krueger, Halma, 2009; Nez, Silva, Silva, 2010; Pitta, Thomaz, Aglaé, Azevedo, Burlamaqui, Gonçalves, 2010; Ribeiro, Martins, Bernardini, 2011; D’Abreu, Bastos, 2013; Guedes, Guedes, Castro, 2013).

Isso por si só já a torna uma ciência interdisciplinar de grandes possibilidades na educação, pois a interdisciplinaridade é a atitude positiva diante do conhecimento, que implica mudança na comportamental diante da tomada de decisões, promovendo a cooperação, o trabalho, o diálogo entre pessoas, entre disciplinas e entre outras formas de conhecimento (Fazenda, 1994).

Nota-se que com os avanços e as novas tecnologias a relação com a sociedade tem mudado drasticamente. Hoje o processo de comunicação por exemplo é feito de forma quase que instantânea e isso não está restrito apenas a comunicação. A tecnologia está fortemente inserida no processo de trabalho, lazer, saúde entre outras tantas áreas, ou seja, a sociedade de forma geral se rende às tecnologias e à modernidade, porém o processo de ensino atual se mostra resistente quanto ao uso destes meios e com isso tora-se ineficiente e de certa forma fechado para estas inserções tecnológicas.

Alguns estudos abordam a robótica educacional em várias atividades escolares como robótica de baixo custo em Medeiros Filhos e Gonçalves (2008), deslocamento em um mapa geográfico por Benitti, Vahldick, Urban, Krueger, Halma (2009). Também existem estudos que abordam o melhoramento do desenvolvimento da expressão escrita, oral, motora e na organização do tempo e do espaço por Nez, Silva e Silva (2010). Em outro estudo o foco é um software de programação em níveis, uma alternativa para o ensino de programação em ambiente da robótica educacional desenvolvido por Pitta, Thomaz, Aglaé, Azevedo, Burlamaqui, Gonçalves (2010).

\subsection{O Programa Institucional de Iniciação a Docência e a Educação Brasileira}

A problemática na educação brasileira é grave quando observa-se que os índices da educação no país, segundo avaliação do Programa Internacional de Avaliação de Alunos (PISA), programa no qual o ojetivo pode ser visto a seguir:

“[...]é uma iniciativa internacional de avaliação comparada, aplicada a estudantes na faixa dos 15 anos, idade em que se pressupõe o término da escolaridade básica obrigatória na maioria dos países. O programa é desenvolvido e coordenado pela Organização para Cooperação e Desenvolvimento Econômico (OCDE). Em cada país participante há uma coordenação nacional. No Brasil, o Pisa é coordenado pelo Instituto Nacional de Estudos e Pesquisas Educacionais Anísio Teixeira (Inep). O objetivo do Pisa é produzir indicadores que contribuam para a discussão da qualidade da educação nos países participantes, de modo a subsidiar políticas de melhoria do ensino 
básico. A avaliação procura verificar até que ponto as escolas de cada país participante estão preparando seus jovens para exercer o papel de cidadãos na sociedade contemporânea. " (Inep, 2011)

Essas avaliações acontecem a cada três anos e fazem parte dele três áreas do conhecimento: Matemática, Leitura e Ciências. O programa de 2009 teve como foco a Leitura, já o de 2012 teve a Matemática. Os dados obtidos em 2012 apontam que o Brasil está ocupando o $58^{\circ}$ lugar na educação entre 65 países avaliados. Ainda assim 731 mil crianças ainda estão fora da escola segundo o PNAD/IBGE do ano de 2011. Outro dado preocupante é que cerca de $34 \%$ dos alunos que chegam ao $5^{\circ}$ ano de escolarização não conseguem ler, e $20 \%$ dos jovens que concluem o ensino fundamental e que moram nas grandes cidades não dominam o uso da leitura e da escrita.

Um levantamento feito pela Confederação Nacional da Indústria (CNI) no final de 2012, mostrou que os investimentos em educação no Brasil nos últimos anos cresceram significativamente, porém comparadondo com países com o mesmo perfil e que fizeram investimentos semelhantes o Brasil está com uma qualidade inferior de ensino em relação aos demais países abordados pela pesquisa (LIMA, 2013).

O PIBID foi criado com a finalidade de valorizar o magistério e apoiar estudantes de licenciatura plena das instituições federais e estaduais de educação superior. Um dos objetivos do PIBID é a elevação da qualidade das ações acadêmicas voltadas à formação inicial de professores nos cursos de licenciatura das instituições públicas de educação superior.

Assim como a inserção dos licenciandos no cotidiano de escolas da rede pública de educação, o que promove a integração entre educação superior e educação básica. $\mathrm{O}$ programa visa também proporcionar aos futuros professores participação em experiências metodológicas, tecnológicas e práticas docentes de caráter inovador e interdisciplinar e que busquem a superação de problemas identificados no processo de ensino-aprendizagem.

O PIBID e os trabalhos com a robótica acontecem nas escolas públicas do município de Francisco Beltrão. Observa-se nas escolas participantes, que apesar dos investimentos em educação elas não estão providas daquilo que realmente necessitam, por exemplo: docentes treinados para utlização das tecnologias, ofertas de cursos para discentes e abertura para uso das tecnologias atuais no processo ensino-aprendizagem.

A região sudoeste do Paraná está em franca expansão quando o assunto é tecnologia, pois existem empresas desse segmento, e na região do município de Francisco Beltrão não é diferente. No entanto, o país apresenta uma escassez de especialistas na area de Tencologia da Informação o que dificulta a criação de novas empresas e até mesmo o crescimento das já instaladas.

Nas escolas onde foram desenvolvidas as atividades de iniciação à docência, são encontrados laboratórios equipados que são subutilizados ou nem mesmo utilizado, um exemplo disso são os laboratórios de química e de informática. Nos de quimica apesar de ter todo equipamento disponível, os professores são despreparados para desenvolver atividades práticas. Nos de informática acontece o oposto: falta profissional educador.

A inserção de qualquer meio de tecnologia, que auxilie no processo de ensinoaprendizagem existem dois grandes interessados: alunos e professores. Com a inserção 
de novos métodos de ensino, envolvendo a tecnologia, possivelmente aumentará o interesse do aluno em aprender e do professor em ensinar. Isso poderá fazer toda diferença na vida profissional do aluno, visto que as tecnologias podem auxiliar no desenvolvimento de muitos aspectos, tais como: do raciocínio lógico e crítico.

Miranda, Sampaio e Borges (2010) citam as vantagens da aquisição de kits de robótica educacional, os quais são: (i) hardware e software construído direcionado a atender propósitos educacionais específicos; (ii) flexibilidade na forma de utilização em diferentes aplicações; (iii) existência de documentação técnica e manual do usuário dos produtos incluindo, em alguns casos, material pedagógico de apoio às atividades do professor em sala de aula; e (iv) maior facilidade para aquisição e operação por usuários não familiarizados/especializados com as tecnologias de eletrônica ou informática.

\section{Metodologia}

O estudo inicial para identificação de mudança ou não no comportamento dos participantes, alunos e professores das escolas, foi realizado por meio de coleta de dados nas escolas estaduais de nível médio que participam do Programa de Institucional de Iniciação a Docência da UTFPR-Campus Francisco Beltrão.

Primeiramente o público pesquisado foram os professores, sendo realizadas vinte e cinco entrevistas por meio de questionários, os quais posteriormente foram tabulados. Os dados coletados serviram de referência para os resultados apresentados neste estudo.

Duas questões, relativas a caracterização do sujeito, procuraram qualificar a faixa etária e formação. A primeira questão procurou identificar a idade dos professores, pois a caracterização da idade dos professores é fundamental para a compreensão dos aspectos que condicionam seu trabalho pedagógico, estrutura e a organização das escolas e as condições de aprendizagem dos alunos (INEP, 2009). Os dados foram tabulados e a distribuição feita por intervalo de idade, em anos, e está apresentada na sequencia:

Tabela 1. Faixa Etária dos Professores de uma escola da rede estadual de ensino do Paraná

\begin{tabular}{c|c}
\hline Idade & Quantidade \\
\hline $20-30$ & 2 \\
\hline $31-40$ & 5 \\
\hline $41-50$ & 15 \\
\hline Mais de 50 anos & 3 \\
\hline
\end{tabular}

A segunda questão procurou identificar a formação do professor em que se considerou a maior titulação para tabular os dados.

Tabela 2: Nível de escolaridade dos professores atuantes em escola de rede estadual de ensino

\begin{tabular}{c|c}
\hline Nível de Escolaridade & Quantidade em \% \\
\hline Superior Completo com & 4 \\
Licenciatura Plena e Pós & \\
Graduação Stricto Sensu & 80 \\
\hline Superior Completo com & \\
Licenciatura Plena e Pós & \\
Graduação Latu Sensu & 16 \\
\hline Superior Completo com & \\
\hline
\end{tabular}




\section{Licenciatura Plena}

As politícas apresentadas pelo governo estão comprometidas com concepções filosóficas e político-pedagógicas que valorizam o professor e buscam promover a aprendizagem efetiva dos alunos, segundo documento da SEB (2005), consideram que a melhoria do processo de ensino-aprendizagem requer ações e programas atinados à natureza do trabalho pedagógico que deve assegurar nos processos formativos (inicial e continuado) o domínio de saberes específicos das diversas áreas do conhecimento, bem como, os conhecimentos relativos às metodologias e a compreensão dos processos de palnejamento, organização curricular, avaliação e gestão da educação escolar.

\section{Resultados}

Durante um período de pouco mais de um ano de inserção do PIBID na escola, pode-se obter, enquanto graduando de Licenciatura em Informática, a experiência de trabalhar na rede pública de ensino, e contato direto com toda rotina escolar, conhecendo com isso suas dificuldades. Um fato que chamou a atenção é a dificuldade que muitos professores têm de inovar em suas aulas, ou seja, de diversificar sua didática. Para identificar o uso de recursos de informática em sala de aula, no questionário, também, foi aplicada algumas questões em relação a esse tema.

Na primeira questão, identifica-se o conhecimento dos professores acerca de informática, onde obteve-se um resultado de $73,4 \%$, ou seja, mais da metade do público alvo sabe utilizar recursos computacionais relacionados a edição de texto, editor de apresentação e slides e $26,6 \%$ sabem utilizar o computador, porém não tem domínio dessas ferramentas. Além disso, questionou-se sobre a utilização de um recurso digital em sala de aula como slides, lousa digital ou algum software específico o qual pudesse auxiliar no processo de ensino, o resultado obtido é mostrado na tabela abaixo:

Tabela 3: Uso de recursos digitais em sala de aula pelos professores atuantes em escola de rede estadual de ensino

\begin{tabular}{c|c}
\hline Resposta & Quantidade em \% \\
\hline Sim, Frequentemente & 40 \\
\hline Sim, raramente & 48 \\
\hline Não Utilizo & 12 \\
\hline
\end{tabular}

Diante do resultado, observa-se que nem todos os professores sabem da importância da utilização de ferramentas tecnológicas no planejamento das atividades de ensino. Com a utilização destas, o aprendizado dos alunos, bem como, o trabalho do professor seria facilitado, assim as aulas tornar-se-iam mais produtivas e atraentes.

Embora os estudos de Duarte (2009) apontem para uma grande resistência na aceitação da tecnologia por parte dos docentes, os dados obtidos por este trabalho mostram que, no universo pesquisado $73,4 \%$ dos professores responderam afirmativamente que a utilização de um software ou ferramentas educacionais digitais trariam algum beneficio as suas aulas enquanto, os demais $(26,4 \%)$ relataram que depende do tipo de aplicação, pois ela pode ser maléfica ao processo de ensinoaprendizagem.

Outra questão abordava se eles tinham conhecimento sobre o que é robótica, pois foram capacitados mais de 20 professores sobre a utilização da robótica em sala de aula 
e $68 \%$ dos entrevistados respondeu que o conhecimento que possuíam acerca da robótica era limitado, ou seja, somente tinham um vislumbre do que seria; $24 \%$ disseram que tinham certeza do que caracterizava a robótica e o restante $8 \%$ tinha total desconhecimento sobre o que constitui a robótica.

Dentre as muitas vantagens pedagógicas do uso da robótica educativa, Zilli (2004), defende que a robótica educacional pode desenvolver as seguintes competências: raciocínio lógico, habilidades manuais e estéticas, relações interpessoais e intrapessoais, integração de conceitos aprendidos em diversas áreas do conhecimento para o desenvolvimento de projetos, investigação e compreensão, representação e comunicação, trabalho com pesquisa, resolução de problemas por meio de erros e acertos, aplicação das teorias formuladas a atividades concretas, utilização da criatividade em diferentes situações, e capacidade crítica. Sendo assim, questionou-se os professores quanto a sua percepção sobre a introdução da robótica em sala de aula, ou seja, quais as expetativas na melhora dos alunos durante as aulas e na última questão abordamos as alterações comportamentais apresentadas pelos alunos que participaram do curso de robótica ofertada, e observamos o seguinte gráfico comparativo as questões:

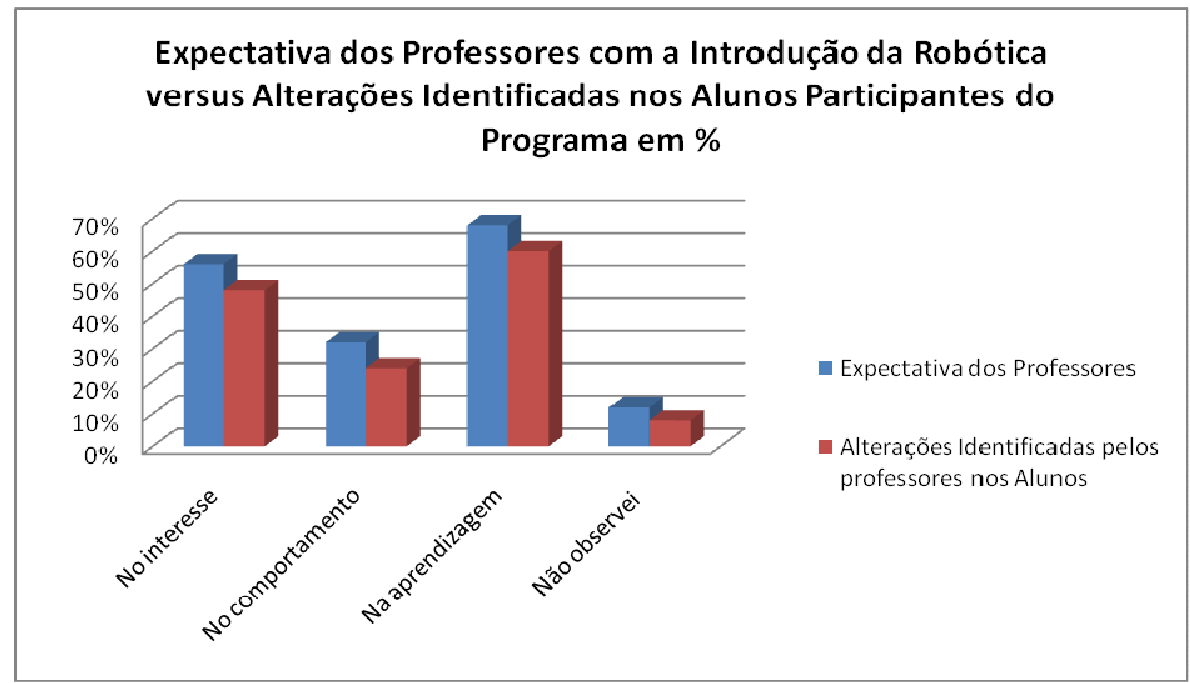

Gráfico 1: A expectativa dos professores com a inserção da robótica e a sua percepção de alterações nos alunos participantes do programa.

Com relação a expectativa dos professores, Papert (1986) afirma que

“[...]dizer que estruturas intelectuais são construídas pelo aluno, ao invés de ensinadas por um professor, não significa que elas sejam construídas do nada. Pelo contrário, como qualquer construtor, a criança se apropria, para seu próprio uso, de materiais que ela encontra e, mais significativamente, de modelos e metáforas sugeridos pela cultura que a rodeia".

E ainda encontramos em Nogueira (1998), p.124, que:

"É papel da escola formar indivíduos, que saibam usar crítica e criativamente o computador - tecnologia social e histórica como o cinema, a fotografia, a pena, a impressão e a escrita. E papel da escola democratizar o acesso a mais um instrumento de criação (humana)" 
A escola tem a missão de preparar o indivíduo para a vida e sente a responsabilidade de não fechar os olhos para a realidade, que muito dependerá de como atende e operacionaliza a educação tecnológica, para que esta venha a contribuir para a aprendizagem e a construção do conhecimento.

Educação e tecnologia estão interligadas, sendo essa condição evidentemente contemplada nas novas propostas de ensino, pois, assim como em outras áreas do saber, na pedagogia a instrumentação da educação deve propiciar um ambiente de convívio saudável, de acordo com a situação vivenciada.

\section{Conclusão}

Uma forma que encontrou-se de demostrar para os professores como é importante a utilização de métodos alternativos se deu com a utilização da robótica, uma aplicação que a princípio pode parecer complexa e em certo ponto até inusitada, mas que se mostra bastante eficiente, pois chama a atenção do aluno e estimula a lógica. A grande vantagem que é notada na aplicação da robótica no processo de educação foi com relação a facilidade que ela tem em prender a atenção do aluno e proporcionar com isso um melhor processo de aprendizagem. É válido dizer que dependendo da criatividade do professor a robótica poderia ser utilizada em matérias que vão além da matemática, física e eletrônica.

Pode-se, por exemplo, incentivar a aplicação dessa tecnologia em outras áreas do conhecimento, tais como: História, onde o professor faça uma aula apresentando quem foi Arquimedes, ao qual é atribuído a invenção da Catapulta, já dando uma ligação para a matemática, onde se explicaria os cálculos envolvidos em equações do segundo grau. Ou seja, o professor de História abordaria Arquimedes, criaria com o kit robótico uma catapulta para demostrar a criação de Arquimedes. A catapulta lança um projétil que forma uma parábola, onde pode-se utilizar diversos cálculos envolvendo Física e Matemática, criando-se uma interdisciplinaridade. Apesar de parecer complexa, existem formas simples de apresentar a robótica para o aluno, um exemplo disso foi à utilização de robôs do tipo LEGO, onde a programação é feita por cubos que são bastante intuitivos e exigem do professor a capacitação.Com isto, ele dependerá da própria capacidade criativa e lógica para propor aos alunos algum conteúdo que gere problema a ser solucionado

Com a inserção no âmbito da docência ainda cursando a graduação, a formação do futuro licenciado se torna mais completa e abre novas possibilidades para aperfeiçoar sua maneira de ministrar as aulas que serão parte de sua vida profissional. Pois é através das intervenções docentes, é que temos a oportunidade de observar experiências de sucesso e de fracasso em relação os processos que estão inseridos na escola e aos profissionais envolvidos. Durante o tempo de capacitação nossa principal dificuldade foi o déficit apresentado pelos alunos em relação ao desenvolvimento de raciocínio logico e a criatividade (fator indicador do fraco ensino da área de exatas, tal como a matemática). Nas aulas iniciais enfatizou-se que deveriam resolver problemas apresentados pelos instrutores. Assim, foram passados os problemas e conceitos envolvidos e coube aos alunos aplicarem estes conceitos na montagem do robô. No entanto, observou-se que nessa fase inicial eles tinham dificuldades em criar e colocar suas ideias em pratica. Por isso, houve a necessidade de intervenção dos instrutores, 
com propostas de desenvolvimento do robô. Com o decorrer do tempo isso melhorou a ponto, no final, deles resolverem os problemas sozinhos, tornando-se independentes. Além disso, formou-se uma demanda considerável de alunos que gostariam de participar do projeto da robótica e devido ao número de kits de robótica LEGO Mindstorms, houve necessidade de trabalhar com turmas de dez alunos e, ainda, dividílos em grupos de cinco durante o desenvolvimento das atividades.

Enfim, o cotidiano no âmbito escolar muitas vezes não permite que o professor tenha acesso a recursos tecnológicos, seja pela escassez do recurso seja pela dificuldade em manuseá-lo, para incrementar sua aula. Porém, com essa experiência dentro das escolas, pode-se perceber que repassar o conhecimento das áreas tecnológicas e incentivar seu uso pode trazer resultados esperados por qualquer docente: a participação, desenvolvimento do pensamento crítico e o aprendizado de seu aluno. Os trabalhos futuros envolvem identificar a melhoria do comportamento e notas dos alunos participantes do PIBID, utilizando comparações entre desempenhos antes, durante e depois da participação.

\section{Referências}

Braga, J.; Dotta, S. C. ; Pimentel, Edson . (2013) Metodologia INTERA para o desenvolvimento de Objetos de Aprendizagem. In: 24 Simpósio Brasileiro de Informática na Educação, 2013, Campinas. Anais do Simpósio Brasileiro de Informática na Educação. São Paulo-Campinas: SBC/Unicamp.

BRASIL, MEC, SEB. Plano de qualidade para a educação básica: Diagnóstico e ações para elevar o nível de qualidade do ensino nas escolas brasileiras, Brasília, março de 2005

D'Abreu, J. V. V.; Bastos, B. L.Robótica Pedagógica: Uma Reflexão sobre a Apropriação de Professores da Escola Elza Maria Pellegrini de Aguiar.(2013) In: II Congresso Brasileiro de Informática na Educação (CBIE 2013), XIX Workshop de Informática na Escola (WIE 2013). Disponível em< http://www.br-ie.org/pub/index.php/wie/article/view/2607/2263> Acesso em 06/07/2014

Dotta, S. C.; Barboza, L. C.; Góis, Jackson; Giordan, M. (2010) Metodologia de Ensino para a inserção das tecnologias de informação e comunicação na prática docente. In: Agustina Rosa Echeverria; Lenir Basso Zanon. (Org.). Formação Superior em Química no Brasil: Práticas e Fundamentos Curriculares. 1ed.Ijuí: Unijuí, p. 241-265.

Duarte, Sinara. Software livre educacional. Revista A rede., n. 50, ago. 2009. Disponível em: <http://softwarelivrenaeducacao.wordpress.com/2009/08/30/reportagem-narevista-a-redesoftware-livre-educacional>. Acesso em: 29 abr. 2012

Fazenda, I. (1994) A interdisciplinaridade: historia, pesquisa e teoria. Campinas: Papirus.

Freire, P. (2002) Pedagogia da autonomia: saberes necessários a prática educativa. São Paulo: Paz e Terra.

Guedes, A. L.; Guedes, F. L.; Castro, T. B. (2013). Perspectivas do uso da Robótica Educativa na Educação Infantil e no Ensino Fundamental. In: II Congresso Brasileiro de Informática na Educação (CBIE 2013), XIX Workshop de Informática na Escola (WIE 2013). Disponível em< http://www.br-ie.org/pub/index.php/wie/article/view/2628/2282> Acesso em 07/07/2014 
INEP. "Pisa - Programme for International Student Assessment". (2011). Disponível em < http://portal.inep.gov.br/pisa-programa-internacional-de-avaliacao-de-alunos $>$ Acesso em $02 / 10 / 2013$

Estudo Exploratório sobre o professor brasileiro: Com base no nos resultados do Censo Escolar de 2007.(2009). Disponível em < http://portal.mec.gov.br/dmdocuments/estudoprofessor.pdf> Acesso em 04 de julho de 2014

Lima, S. S. "Educação: um fator muito importante que pode mudar uma nação" (2013) In: USP. Disponível em < http://www.fea.usp.br/econoteen/media/fck/File/Samira\%20dos\%20Santos\%20LimaEducac ao_um_fator_muito_importante_que_pode_mudar_uma_na\%C3\%A7\%C3\% A3o.pdf $>$ Acesso em 01/10/2013

Medeiros, D. A.; Gonçalves, P. C. (2008). Robótica Educacional de Baixo Custo: Uma Realidade para as Escolas Brasileiras. In: Workshop sobre Informática na Escola, Belém, Anais do XXVIII Congresso da SBC. Disponível em: < http://www.brie.org/pub/index.php/wie/article/view/985/971> Acesso em 05/05/2014

Miranda, L. M., Sampaio F. F., Borges J. A. S. (2010) RoboFácil: Especificação e Implementação de um Kit de Robótica para a Realidade Educacional Brasileira. Disponível em <http://www.br-ie.org/pub/index.php/rbie/issue/view/39>, RBIE V.18. N.3 - 2010, acesso em 20 de janeiro de 2014.

Nez, E.; Silva, A. M.; Silva, E. M. TRANSDISCIPLINARIDADE ATRAVÉS DA ROBÓTICA: Um relato de experiência na Escola Pública do Estado de Mato Grosso(2010). In: Workshop sobre Informática na Escola. Disponível em: < http://www.br-ie.org/pub/index.php/wie/article/view/2075> Acesso em 06/05/2014

Nogueira, L. (1998) Imagens da criança no computador. In: KRAMER, S., LEITE, M. I. F. P. (Org.). Infância e produção cultural. Campinas: Papirus.

Papert, S. (2008) A máquina das crianças: repensando a escola na era da informática. Porto Alegre: Artmed.

Pitta, R.; Thomaz, S.; Aglaé, A.; Azevedo, S.; Burlamarqui, A.; Gonçalves, L. M. RoboEduc: Um Software para Programação em Níveis (2010). Workshop sobre Informática na Escola. Disponível em: $<$ http://www.brie.org/pub/index.php/wie/article/view/2073/1835> Acesso em 06/05/2014

Ribeiro, P. C.; Martins, C. B.; Bernardini, F. C. A Robótica como Ferramenta de Apoio ao Ensino de Disciplinas de Programação em Cursos de Computação e Engenharia(2011).In: Anais do XXII SBIE - XVII WIE, Aracaju. Disponível em < http://www.brie.org/pub/index.php/wie/article/view/1951/1710> Acesso em 07/06/2014

Vahldick, A. ; Benitti, Vavassor, F. B.; URBAN, D. L. ; KRUEGER, M. L. ; HALMA, A. (2009) O uso do Lego Mindstorms no apoio ao Ensino de Programação de Computadores. In: Congresso da Sociedade Brasileira de Computação, Bento Gonçalves. XXIX Congresso da Sociedade Brasileira de Computação, p. 523-526.

Zilli, S. R. (2004) A robótica educacional no ensino fundamental: perspectivas e práticas. Santa Catarina. Dissertação de Mestrado - Programa de Pós - Graduação em Engenharia de Produção, Universidade Federal de Santa Catarina. 